\title{
A alteridade como fato e justificativa para a escrita de histórias da literatura
}

\section{The otherness as a fact and a reason for the writing of literary histories}

Ana Maria Coelho Silva Wertheimer ${ }^{1}$

Doutoranda em Teoria da Literatura do Programa de Pós-Graduação da Faculdade de Letras da Pontificia Universidade Catolica do Rio Grande do Sul - PUCRS. ana.wertheimer@pucrs.b.
RESUMO: 0 presente artigo tem por objetivo discutir a estrutura narrativa de possíveis História(s) da Literatura, a partir da articulação de conceitos de Certeau e de Paul Ricœur sobre a escrita da História. A abordagem sistêmica de Grumbrecht e os elementos narratológicos propostos por David Perkins para a construção de história(s) da literatura parecem pactuar com questões contemporâneas de identidade e pertencimento de grupos marginalizados (alteridade) que buscam seu espaço na representação literária.

PALAVRAS-CHAVE: História da literatura; Narrativa; Alteridade.

ABSTRACT: This article aims to discuss the narrative structure of possible Literary History(ies), as from the articulation of concepts of Certeau and Paul Ricoeur on the writing of History. The systemic approach of Grumbrecht and the narratological elements proposed by David Perkins for the construction of literary history(ies) seem to go along with contemporary issues of identity and belonging to marginalized groups (otherness) seeking their places in the literary representation.

KEYWORDS: Literary history; Narrative; Otherness.
[...] uma história da literatura, seja a literatura de uma nação, classe, região, raça ou gênero, iria ajudar a elucidar quem somos individualmente e como comunidade.

David Perkins (1992, p. 180-181. Tradução nossa) 


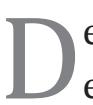
entre as possíveis contribuições da História da Literatura (HL) para a evolução da humanidade, destacamos uma que comprova a relevância desta disciplina para discussões que ultrapassam os domínios da estética: a formação da identidade de uma nação ou de grupos sociais marginalizados (em consonância com os debates da atualidade). Antes, entretanto, de discorrermos sobre o caráter formador de uma HL na contemporaneidade, é preciso que façamos algumas considerações a respeito dos princípios que regem a operação historiográfica bem como dos elementos que norteiam a escrita de uma História. Estabelecidos estes conceitos, passaremos a questão central deste estudo: o que e como pode uma HL representar para além de um conjunto de cânones literários, elencados por uma ordem cronológica?

O ponto de partida para a nossa discussão são as particularidades da operação historiográfica no processo de escrita da História ${ }^{1}$. Para o erudito francês Michel de Certeau (2003), a História, como qualquer sistema de pensamento, não visa à reconstituição da verdade, o que parece ser incoerente para qualquer disciplina que busque rigor científico. A cientificidade da História, no entanto, é atingida mediante um certo grau de subjetividade (o que, a priori, sinaliza uma contradição), presente na combinação de três fatores: lugar social, práticas científicas e texto. "Antes de saber o que a história diz de uma sociedade, é necessário saber como [a história] funciona dentro dela" (CERTEAU, 2003, p. 76. Grifo do autor).

O historiador francês alega que toda História configura-se a partir de um sistema (ou lugar social) no qual a própria História se produz, no qual os fatos históricos acontecem. Desta relação 'história-lugar', criam-se condições para uma análise da sociedade que possibilita a escrita de uma (ou de sua)

\footnotetext{
${ }^{1}$ Segundo o filósofo francês Paul Ricœur (2007), é um equívoco aplicarmos à terceira fase da operação historiográfica o título de 'escrita da história' ou 'historiografia', visto que a história é, em si, uma escrita, disto filós a fase docu rental (levant "repro do não historiadora" (RICOEUR, 2007. p. 247). Para fins deste artigo, manteremos a expressão 'escrita da História'.
}

História. A aparente circularidade, em que um elemento, simultaneamente, causa e é causado por outro, ocorre porque o autor da História sempre interpretará seu objeto de estudo dentro de um lugar social. Por mais que se apoie em documentos para assegurar cientificidade à operação historiográfica, o historiador, por também pertencer a um sistema, é incapaz de realizar uma pesquisa de modo absolutamente imparcial.

Assim como não pode ser isenta, a História também não pode ser global e unificada, por mais ambiciosos (ou presunçosos) que sejam os projetos. Cabe ao historiador a tarefa de selecionar suas fontes e de delimitar o objeto a ser estudado. Os métodos e técnicas para a manipulação do material, metodologicamente justificados, são determinantes para a transformação da natureza em cultura, ou, no caso da História, para a conversão de fatos históricos na própria História. Como que inserido em um grande "canteiro de obras" (CERTEAU, 2003, p. 78), o historiador separa, reúne e converte a matéria prima (a informação primária) em material utilitário (documentos históricos). É neste ponto da operação historiográfica que encontra-se o limiar entre a objetividade e a subjetividade da construção da História: ao mesmo tempo em que os procedimentos para uso do material asseguram o valor científico do objeto a ser estudado (a documentação), esses mesmos procedimentos conferem ao estudo um grau de subjetividade, dado ao fato de haver a intervenção (inevitável) do historiador para a constituição do próprio objeto, para a seleção do corpus.

Sua prática [prática da nova história] consiste em construir "modelos" propostos decisoriamente, em substituir o estudo do fenômeno concreto pelo estudo de um objeto constituído por sua definição, em julgar o valor científico deste objeto [...], em fixar os limites da significabilidade desse modelo. (CERTEAU, 2003, p. 84. Grifo do autor).

Enquanto a pesquisa historiográfica pode ser um processo perene e inesgotável, a escrita da História deve ser manipulada pelo historiador que, 
além de selecionar fontes, também define os pontos de início e término de seu estudo, a fim de viabilizar o relato. Dentre as considerações que Certeau apresenta sobre o processo de escrita, destacamos a "inversão escriturária" (CERTEAU, 2003, p. 94) e o tempo discursivo. Por inversão, entendemos que a escrita da História é concebida em sentido contrário, ou seja, do final para o início, do presente para o passado. Há aí um afastamento inevitável entre historiador (que pertence ao tempo presente da escrita) e seu objeto (que é histórico). Por tempo discursivo, Certeau defende que, na escrita historiográfica, o tempo pode ser expandido ou condensado, acelerado ou procrastinado, dependendo das intenções daquele que relata.

Os três fatores apontados por Certeau (lugar social, práticas científicas e escrita do texto) atribuem à operação historiográfica uma certa relatividade, uma subjetividade, perceptível tanto na delimitação e interpretação do objeto de estudo, quanto na própria escrita da História. ${ }^{2}$ Paul Ricœur (2007) divide a operação historiográfica em três fases (a saber, documental, da explicação e da representação historiadora) que, aparetemente, coincidem com as considerações de Michel de Certeau (2003). Para ambos teóricos, na operação historiográfica, mais do que meramente reproduzidos, os fatos históricos são, antes, constituídos pelo historiador, em (três) etapas que ocorrem simultaneamente, isto é, que "não constituem estágios sucessivos, mas sim níveis intricados aos quais somente a preocupação didática confere uma aparência de sucessão cronológica". (RICCEUR, 2007, p. 247).

Transpondo as considerações acerca das práticas científicas do campo da historiografia para o domínio da História da Literatura (HL), destacamos

\footnotetext{
2 As três fases da operação historiográfica apresentadas por Paul Ricœur (2007), a saber, a fase documental, da explicação e da representação historiadora, coincidem, de certa forma, referidas nas
consideraçôes de Michel de Certeau (2003) e vice-versa. É importante destacarmos que tanto as três fases quanto os três fatores a resentar três fases quanto os tres fatores apresentam-se concomitantemente, isto é, "não constituem estágios sucessivos, mas simén aparencia de sucessão cronologica". (RICÆEUR, Paul. A memória, a história e o esquecimento. Campinas, SP: Editora
da Unicamp, 2007. p. 247).
}

o estudo do Professor de Literatura Inglesa e Americana da Universidade de Harvard, David Perkins (1992), que discute a possiblidade de se escrever uma HL “intelectualmente respeitável” (PERKINS, 1992, p. 12. Tradução nossa), isto é, a possibilidade de se atribuir à HL um valor científico. Para tanto, Perkins assegura que toda a HL deve constituir uma narrativa e apresentar os elementos estruturais previstos no discurso. "[...] uma história literária narrativa não ajusta-se integralmente como história, porque é uma narrativa. Mas [...] ela não se adere como uma narrativa, porque é também crítica e história." (PERKINS, 1992, p. 40. Tradução nossa)

Uma das grandes questões que instigam os teóricos da literatura, e que Perkins adota como título de sua obra (Is literary history possible?), diz respeito à possibilidade de escrever-se uma HL intelectualmente respeitável, isto é, à possibilidade de atribuir-se um valor científico ao estudo historiográfico da literatura. Para discutir essas questões, Perkins apresenta os objetivos da HL, que, segundo o professor, são:

a) Retomar a literatura do passado, incluindo obras raramente lidas;

b) Organizar o passado pela seleção e classificação de autores e textos em grupos interconectados;

c) Interpretar trabalhos literários e relacioná-los aos seus contextos históricos;

d) Descrever os estilos e as visões de mundo ${ }^{3}$ de textos, autores e épocas;

e) Disponibilizar o conteúdo e citações de obras, uma vez que muitos leitores não terão outra forma de acesso a estas obras;

f) Através da seleção, interpretação e avaliação, trazer o passado até o presente, com consequências para a literatura e para a sociedade do futuro.

${ }^{3}$ Perkins (1992) não traduz a expressão Weltanschauungen para a língua inglesa. 
Conhecidos os objetivos que devem orientar a escrita da HL, podemos identificar no mínimo dois que convergem para os conceitos de Certeau e de Ricœur sobre a subjetividade na construção da História. O primeiro deles é a temporalidade. Toda HL deve representar o passado, isto é, deve descrever e explicar o passado, desvelando os critérios que, por justificativas plausíveis, congregam um conjunto de obras literárias. Certamente, a representação do passado não é (e não poderia ser) completa, pois tratase de uma interpretação deste passado, tempo que pode apresentar-se mais distante ou mais próximo do tempo presente. A metodologia de uma operação historiográfica prevê, pois, a incompletude das representações e a parcialidade das explicações, desde que justificadas coerentemente, uma vez que não há como estudar todo o passado nem todas as obras. Entretanto, quaisquer omissões arbitrárias (obras que não constam no corpus préestabelecido por uma metodologia acordada) serão consideradas distorções do passado, o que invalidará o caráter científico do relato.

Neste ponto, pode-se estabelecer a intercessão com o debate de Gumbrecht (1996) a respeito do caráter fragmentário da HL. Ciente da "crise da noção de totalidade histórica" (1996, p. 225), Grumbrecht argumenta em favor da substituição do conceito de "totalidade" por "mentalidade" (ou saber social). Mentalidade constitui a uma matriz comum a todas as ciências históricas que age como um elemento organizador das disciplinas. A mentalidade permeia todos os diferentes tipos de comportamentos e ações que serão (possivelmente) reconstruídos pelas HL na representação ou explicação do passado. A literatura, de acordo com Grumbrecht, passa a ser um meio para se conhecer a totalidade, um sintoma da história global, como a pequenina peça de um quebra-cabeça (fragmento) ao compor a grandiosa imagem (todo).

Embora Perkins e Grumbrecht abordem a construção da HL sob dois aspectos distintos, aquele narrativista e este sistêmico, ambos reconhecem a impossibilidade de construir-se uma HL completa. A totalidade seria o próprio passado e não uma interpretação (uma explicação) deste passado, como é proposto hoje na operação historiográfica. Dessa forma percebemos que a noção de fragmento está presente em ambos os modelos e é possível concluirmos que o componente narrativo de que trata Perkins encontra-se dentro de um único sistema que, por sua vez, conecta-se com outros sistemas e que igualmente possuem seus discursos narrativos.

Outro aspecto apontado nos objetivos da HL de Perkins, e que está associado à subjetividade discutida por Certeau e Ricœur, é a necessidade de haver uma seleção de obras literárias para viabilizar um estudo historiográfico da literatura: a seleção de um passado. Questões polêmicas, e previsíveis, surgem para uma seleção desta natureza: que gêneros devem ser incluídos em uma HL? Além de prosa, poesia e drama, que outros gêneros podem ou devem compor um corpus? Ao analisar algumas HL que têm como referência o século XIX, Perkins (1992) identifica a inclusão de discursos políticos, filosóficos e científicos como obras literárias, e argumenta que essa inclusão visava à expansão do campo de atuação da literatura para uma tentativa de compreender as emoções e pensamentos (expressos pelas obras), os ideais e os valores morais de seus autores, bem como os comportamentos e as instituições da sociedade.

Após um período de hegemonia no fecundo século XIX, em que a HL teve grande relevância no contexto social, oportunizando a formação da identidade de regiões e de nações, a HL passa a ser criticada por seus critérios de seleção e sua credibilidade é enfraquecida. Também os Formalistas Russos (entre 1926 e 1928) criticaram a HL, pois, embora admitissem o seu valor, criticavam a interferência de fatores externos (dados externos correlativos, como, cartas, cadernetas, diários, manuscritos, entre outros) na composição de um corpus literário (cf. PERKINS, 1992, p. 8). Para Perkins (1992), somente no final do século XX, podemos constatar a revitalização da 
HL que, para além das evidentes razões acadêmicas e comerciais (a saber, a visibilidade de intelectuais e a produção de novos materiais em torno de um tema já em desuso), pode também ser motivada pela possibilidade de uma redistribuição das obras literárias ou pela inserção de outras obras que ainda permanecem à margem dos cânones ou obras que, fazendo aqui uma breve alusão à dialética de Paul Ricœur, permanecem no esquecimento.

Os movimentos para libertação das mulheres, negros e homossexuais produzem histórias literárias, pelos mesmos motivos, essencialmente, que inspiraram as histórias literárias nacionais e regionais do século XIX. (PERKINS, 1992, p. 10. Tradução nossa)

Uma vez que atribuímos à HL a construção de representações do passado (construções reconhecidamente parciais e incompletas, devido a seleções subjetivas de textos e/ou autores), passam a existir Histórias da literatura (um discurso múltiplo) e não mais uma única História que abarque, presunçosamente, a totalidade. Uma HL factível nunca será completa, mas, por meio de uma metodologia rigorosa e consistente, é possível definir o quanto de incompletude será aceitável para a escrita de uma HL completa, dentro de seus limites e segundo seus critérios. Como a peça de um quebra-cabeça, uma HL deve ser completa em si para encaixar-se na totalidade.

Nesse sentido, é inevitável que aceitemos a existência, não mais de uma única história (pretensamente totalitária e completa), mas de diversas histórias da literatura. Perkins admite que "histórias literárias podem evidenciar diferentes momentos do processo total. [...] Idealmente, uma história literária iria perseguir todos esses momentos, mas esse ideal é utópico e não pode ser realizado na prática." (PERKINS, 1992, p. 23. Tradução e grifo nossos). Ainda nessa perspectiva, também o historiador francês François Furet (1986) assegura a pluralidade da HL:
[...] não se deve deduzir que a história deve regressar à sua função antiga de contadora de excelentes aventuras. Devemos antes aceitar a redução das ambições pouco razoáveis da história total, para utilizar [...] as descobertas sectoriais [...]. O preço a pagar [...] é o estilhaçar da história em histórias [...]. (FURET, 1986. p. 98)

Perkins (1992) discute, ainda, duas formas para construção de uma HL: uma enciclopédica e outra narrativa, ambas tradicionais por retomarem a HL linearmente, dentro de uma ordem cronológica. A HL enciclopédica constitui uma antologia de obras publicadas, reunidas, geralmente, em função da data de sua publicação.

A forma enciclopédica é livre. 0 escritor pode incluir qualquer informação [...] Desse modo, obras no formato enciclopédico podem misturar biografia bibliografia, história intelectual, história social, informação sobre a recepção das obras e sobre crítica, deslocando-se de um para outro com uma flexibilidade que não pode ser encontrada em uma história narrativa. (PERKINS, 1992, p. 54. Tradução nossa)

Como exemplo de história enciclopédica, Perkins apresenta a obra Oxford Companion to English Literature, cuja primeira edição é de 1932. Nela os verbetes estão dispostos, pura e simplesmente, em ordem alfabética, numa "possível tentativa de contemplar nossas suspeitas a respeito da multiplicidade e heterogeneidade do passado" (PERKINS, 1992, p. 55). 0 autor de Is literary history possible? pondera que a HL enciclopédica aproxima-se mais da prática científica do que a história narrativa da literatura (HNL), visto que o critério para a seleção das obras em uma antologia é o período em que as obras foram publicadas.

Na perspectiva narratológica, entretanto, Perkins legitima o emprego de elementos da narrativa tradicional (herói, enredo e temporalidade) para a escrita de uma HNL. Perkins (1992) sugere que o enredo deva assumir a função de fio condutor para a seleção os cânones, o que garantirá a coerência 
de uma HNL. Ainda que toda escolha seja subjetiva e arbitrária, quanto mais plausível e coerente for o enredo de uma HNL (justificando o recorte de um corpus), maior o grau de cientificidade desta História. Embora subjetiva e parcial, uma HNL, dentro de seu projeto) deverá ser completa, esférica, sem lacunas ou excessos que comprometam a sua solidez.É papel do historiador almejar a totalidade dentro da parcialidade de uma HNL.

Uma história da literatura não pode ter apenas um texto com seu tema e não pode descrever os textos individualmente. A multiplicidade de objetos deve ser convertida em unidades menores e mais manipuláveis que poderão, depois, ser caracterizadas, comparadas, inter-relacionadas e ordenadas. (PERKINS, 1992, p. 61. Tradução nossa)

O herói em uma HNL caracteriza-se por uma entidade que, de algum modo, passa por uma transformação (enredo) dentro de um intervalo de tempo (temporalidade). O herói na HNL consiste um indivíduo social ou um assunto ideal a partir do qual será selecionado um conjunto de obras literárias. O herói pode ser considerado o ponto de vista, o foco, a partir do qual um estudo historiográfico será orientado. É fundamental, entretanto, que este herói passe por uma transformação, por uma mudança (que na narração corresponde ao enredo), dentro de um determinado período (o tempo da narrativa). Todo tempo narrativo prevê um recorte arbitrário (início e fim), porém justificável pelo próprio enredo e pelo herói da HNL. Uma vez cientes de que o historiador deve eleger os três elementos da estrutura narrativa para construir o seu relato, passamos a reconhecer a subjetividade da HL.

Perkins (1992) apresenta algumas obras do gênero HNL para ilustrar como os elementos da narrativa estão nelas inseridos. Na História da literatura alemã desde a morte de Lessing, por exemplo, escrita pelo historiador alemão Julian Schmidt (1818-1886) no ano de 1866, o espírito do Iluminismo constitui o herói da História. Nela, o momento fundador é instituído pelas "primeiras lutas da sã compreensão e sentimento humanos contra a coerção da Igreja” (PERKINS, 1992, p. 30) e o desfecho se dá por volta de 1866, ano da publicação da obra. Um exemplo do mesmo gênero dentro da literatura brasileira, destacamos a obra do escritor Joaquim Norberto de Souza Silva (1820-1891), intitulada Modulações Poéticas, do ano de 1841. A nacionalidade, o “cantar a pátria” (ZILBERMAN; MOREIRA, 1998, p. 96), parece ser o herói em torno do qual a obra se desenvolve. A luta pela autonomia e a necessidade de constituir-se uma nação livre e independente são marcas do Segundo Império do Brasil que busca encontrar, também através da escrita de uma HL, a legitimação da identidade de sua jovem nação.

Para além do herói e do enredo, a HNL caracteriza-se, outrossim, pelo tempo, isto é, pelo intervalo no qual um conjunto de obras deverá ser formatado. Tomando novamente o texto do historiador brasileiro da primeira metade do século XIX, Joaquim Norberto de Sousa Silva, o recorte temporal utilizado por este historiador corresponde ao intervalo que inicia no descobrimento do Brasil até o momento da produção da sua obra, o ano de 1841. Sobre o aspecto temporal das Modulações poéticas, vale uma observação referente à diversidade das partes que compõem a obra: talvez pela dificuldade de encontrar as fontes ou, provavelmente, pela escassez de obras genuinamente brasileiras, que contemplassem o espírito nacional preconizado pelo historiador (o herói de sua HNL), a primeira época desta história agrupa dois séculos inteiros, mas contempla apenas cinco escritores. Já a quinta etapa do mesmo projeto abarca pouco mais de dez anos, porém, nela é apresentado um grupo de trinta autores. Talvez aqui tenhamos de considerar fatores externos que possam ter contribuído para esta discrepância: a quinta etapa da HL de Joaquim Norberto tem por marco fundador a Proclamação da Independência Nacional (1822) e se estende, presumidamente, até 1836, com o evento que 
o autor institui como uma "Reforma da Poesia" (ZILBERMAN; MOREIRA, 1998, p. 135). A publicação das poesias de Gonçalves de Magalhães, "o gênio fluminense" (p. 105), o protagonista de um grupo de poetas nacionais que sentiram a "necessidade de adotar instituições diferentes das que lhe impunham a Europa" (p.135), retrata com clareza o espírito da época: a busca pela instituição da nacionalidade brasileira. Hoje percebemos que tratava-se do início do Romantismo no Brasil. Joaquim Norberto escrevia sobre seus contemporâneos, o que, por si, já constitui uma inovação, dado que, na operação historiográfica, a história é do tempo passado, anseia pela construção de representações do passado. Na procura de uma identidade nacional, Joaquim Norberto incorporou à sua HL obras e escritores de sua época, foi audaz o suficiente para dar voz uma poesia nacional: a certificar a alteridade.

Chegamos, enfim, ao ponto central do nosso estudo: o papel de uma HNL como formadora de identidade, como colaboradora na formação da consciência de um grupo social. Um exemplo evidente é a aclamação do espírito nacional na (e para a) fundação de uma literatura brasileira autônoma, ideia defendida por intelectuais do século XIX, neste trabalho representados Joaquim Norberto de Sousa Silva em suas Modulações Poéticas. Talvez despretensiosamente, Histórias como a de Joaquim Norberto contribuíram não apenas para a formação da literatura brasileira, mas da própria identidade da nação e do imaginário nacional.

O literato uruguaio Hugo Achugar (2003) discute sobre o surgimento das pátrias latino-americanas e aponta as letras e as artes plásticas, bem como as celebrações cívicas (hinos e bandeiras) e até mesmo a economia (moeda), como instrumentos que oportunizaram (e oportunizam) a fundação de uma memória nacional. Achugar ratifica o pressuposto da literatura como fundadora da nação e vai além: denuncia que o discurso fundante dos estados-nação da América Latina no século XIX era elitista e excluiu certos grupos sociais, como a mulher, os índios, os negros e, em muitos casos, os que não possuíam propriedades. "Esse perfil do sujeito enunciador [do discurso fundante] contribui, por sua vez, para a construção do perfil de um sujeito da nação (o cidadão) que se identificou com o discurso de certo nacionalismo", destaca Achugar (2003, p. 50. Grifo nosso).

Parece-nos pertinente que, uma vez instituída a independência e a autonomia da nação, devamos, agora, saldar as dívidas do passado e ocuparnos com a construção de novas histórias da literatura (histórias narrativas da literatura) que contemplem as expressões de culturas e identidades múltiplas existentes em território tão vasto e miscigenado como o Brasil. O professor de Estudos Brasileiros e Judaicos da universidade norte-americana Brown University, Nelson Vieira, argumenta que, sob a ótica do hibridismo e da alteridade, devemos reavaliar "como e por que certas culturas ou obras estão incluídas ou excluídas da história literária - excluídas ou marginalizadas" (VIEIRA, 2003, p. 96. Grifos do autor). Com o intuito de buscar uma história literária que seja "mais representativa da redemocratização cultural que está acontecendo no Brasil" (2003, p. 97), Vieira preconiza o reconhecimento de "culturas esquecidas" (VIEIRA, 2003. p. 98), de uma multiplicidade cultural que deve ser incluída numa HL. O literato defende uma nova configuração da HL para a inclusão do discurso (ou das vozes) dos esquecidos, dos ignorados ou marginalizados, daqueles que podem causar "um certo desconforto cultural" (VIEIRA, 2003, p. 98).

Os debates acerca da estética contemporânea defendem, pois, o reconhecimento e a inserção de gêneros que permanecem à margem dos estudos literários e, consequentemente, da HL. A exemplo do século XIX em que a HL abarcou discursos políticos, filosóficos e científicos, visando à expansão do campo literário, o discurso contemporâneo tem-se apresentado ainda mais flexível e permeável, questionando não apenas o meio de veiculação, como também o próprio formato da obra literária. 
Estudiosos como a crítica argentina Florencia Garramuño (2014) defendem a expansão da literatura tanto para outras mídias como para outras formas de texto. Garramuño (2014) alega que, em razão dos avanços tecnológicos, surgiram novas práticas estéticas, novas "explorações literárias” (2014, p. 65), que justapõem linguagem verbal e não-verbal, texto escrito e imagem, em gêneros atuais como blogs, chats, redes sociais, e-mails, entre outros. $\mathrm{O}$ discurso testemunhal (como a autobiografia, as memórias ou os textos documentários) constitui uma vertente dentre as estratégias narrativas contemporâneas. Tal discurso caracteriza-se como um gênero literário híbrido que permeia entre o fato e a ficção, cuja estratégia narrativa alude a pelo menos três vozes distintas, aparentemente amalgamadas: a voz do personagem, a do narrador e a do autor.

Um discurso protagonizado por um "eu" que possa corresponder ao próprio autor, por si só, já justifica a diversidade das novas práticas estéticas que, tendo em vista o grande número de publicações produzidas na atualidade, reivindicam seu lugar no cânone literário. Garramuño ainda inclui as "combinações inesperadas" (2014, p. 64) que articulam textos escritos a instalações artísticas ou objetos o que extravasa os limites do formato livro e as fronteiras disciplinares. 0 texto, nesta perspectiva mais arrojada, constitui muitas vezes fragmentos, "prosas curtas inclassificáveis" (cf. Garramuño, 2014, p. 64).

Garramuño apresenta exemplos de obras brasileiras contemporâneas que representam este 'não pertencimento', ou seja, de obras inespecíficas e autônomas, que parecem evidenciar a ideia de desconforto sugerida por Vieira (2003). 0 termo desconforto é também utilizado por Garramuño e adapta-se ao sentimento suscitado por todo elemento inovador, independentemente da época em que se insere. Garramuño ainda nomeia as manifestações artísticas sui generis da literatura mais recente como 'Fruto estranho', expressão inspirada no título da instalação do artista brasileiro
Nuno Ramos que articula gêneros distintos, caracterizando uma verdadeira expansão das linguagens artísticas.

Há um número de regras que regem a prosa literária e, da combinação destas categorias, resulta o gênero romance. Esta combinação determina a riqueza e a variedade da narrativa em prosa. Os romancistas, considerando esgotadas as possibilidades de inovação relativamente a temas e personagens, buscam a novidade nas técnicas narrativas, segundo afirma Oscar Tasca (1983). À crítica literária cabe, pois, a análise da obra de caráter insólito, criada a partir das novas técnicas. Esta análise tem por fim mostrar para o leitor comum a passagem de uma desordem para uma ordem, do nãosignificante para a coerência das significações, do informe para a forma, do vazio para a plenitude, da ausência para a presença. Segundo Garramuño (2014), para uma obra de arte inespecífica, que propõe outros modos de organizar os relatos, há que se ter uma crítica da arte e da literatura contemporâneas igualmente inespecífica (cf. Garramuño, 2014, p. 71), que não se proponha a identificar novos modos de pertencimento, mas que reconheça o inespecífico como a elaboração de formas do não pertencimento.

A revolução que se produz na arte e na crítica do literária nasce no momento em que o leitor pergunta: quem fala? de onde fala? o que é romance? O romance está no texto e nas entidades que este estabelece. Para uma resposta simples, podemos dizer que romance é um relato assumido por um narrador, numa determinada forma ou pessoa ( $1^{\underline{a}}$ pessoa ou $3^{\underline{a}}$ pessoa), que alude a um tempo e nos põe em contato com personagens. Porém, cada uma dessa entidades (narrador, personagens, tempo) se constituem exclusivamente no plano do discurso. Estas entidades, parecem dialogar como novas perspectivas, novos espaços. Ao discorres sobre as expressões da literatura brasileira no século XXI, a professora da Universidade Federal do Rio de Janeiro, Beatriz Resende (2008), atesta que 
A maior novidade, porém, está seguramente na constatação de que novas vozes surgem a partir de espaços que até recentemente estavam afastados do universo literário. Usando seu próprio discurso, vem hoje, da periferia das grandes cidades, forte expressão artística que, tendo iniciado seu percurso na música, chega hoje à literatura. (RESENDE, 2008, p. 17)

Resende (2008) destaca pelo menos seis elementos que podem caracterizar a prosa da ficção brasileira contemporânea, e que talvez retratem expressões artísticas contemporâneas de outras nacionalidades, são eles: a fertilidade, a juventude, a multiplicidade, a presentificação, o retorno ao trágico e o excesso de realidade. A professora inicia a sua lista pela democratização da literatura, uma vez que há um número grande e crescente de editoras, de escritores e, consequentemente, de publicações. "Apesar das queixas repetidas de que há poucos leitores, de que o livro vende pouco, etc. é fácil constatar que se publica muito, [...]" (RESENDE, 2008, p. 16). Por fertilidade, Resende entende este aumento na produção de livros e destaca que o escritor jovem não espera pelo reconhecimento da academia ou do mercado e publica da forma que lhe é possível: de forma independente ou por meio da internet. Seu propósito é ser lido.

Em decorrência da fertilidade e da juventude, as expressões literárias contemporâneas apresentam múltiplos formatos, mesclando linguagens, temas e suportes (multiplicidade), ultrapassando os limites literatura convencional para a inclusão de expressões culturais distintas. A relevância do tempo presente, talvez por descrença no futuro, é mais um aspecto das formações culturais contemporâneas: a presentificação é relevada nos textos curtos, nas mininarrativas, nas obras "para serem lidas de um só fôlego" (RESENDE, 2008, p. 128).

Outra característica é a violência da vida cotidiana nas grandes cidades brasileiras como tema de textos narrativos, que deflagra o retorno ao trágico na literatura. A função do trágico, numa visão aristotélica clássica, é tornar a vida suportável pelo consolo da arte. Resende (2008) ainda aponta que esta função da obra literária articula-se ao tempo presente (presentificação): o tempo do discurso e o tempo da recepção da obra. 0 tema da violência urbana, da solidão e da angústia podem refletir o excesso de realidade das narrativas contemporâneas; excesso pela proximidade narrador-autor, em textos que revelam um discurso mais testemunhal e autobiográfico do que ficcional.

Pensar o presente no campo da literatura proporciona indagações sobre as novas tendências da estética da ficção. As obras literárias do século XXI devem também ser incluídas no corpus de Histórias que narrem a contemporaneidade. Cabe, pois, aos estudiosos da literatura, aos novos 'Joaquins Norbertos', a tarefa de resgatar o díspar, o dever de escrever, não uma história completa e totalitária (o que reconhecemos ser infactível), mas histórias da literatura brasileira que representem diferentes vozes, com autores e obras que, por algum motivo, foram (e muito provavelmente ainda sejam) rejeitados por um grupo dominante que impõe uma ideologia ou um "patrimônio nacional" (VIEIRA, 2003. p. 102). As novas histórias da literatura contribuirão não apenas para registrar, mas também para dar voz e valor a múltiplos discursos definidos por raça, gênero, etnia, condição física, entre outros, o que garantirá uma HL mais democrática e mais representativa da nossa época de das nossas culturas.

\section{Referências}

ACHUGAR, Hugo. A escrita da história ou a propósito das fundações da nação. In: MOREIRA, Maria Eunice (Org.). Histórias da literatura: teorias, temas e figuras. Porto Alegre: Mercado Aberto, 2003. p. 35-60.

CERTEAU, Michel de. A escrita da história. Rio de Janeiro: Forense Universitária, 2003. FURET, François. Da história-narrativa à história-problema. In: Lisboa: Gradiva, 1986. Vol. I, p. 81-98. . A oficina da história. 
GARRAMUÑO, Florencia. Frutos estranhos. A aposta pelo inespecífico na estética contemporânea. In: OLINTO, Heidrun K.; SCHØLLHAMMER, K. E. (Org.) Cenários contemporâneos da escrita. Rio de Janeiro: 7Letras, 2014.

GUMBRECHT, Hans Ulrich. História da literatura: fragmento de uma totalidade desaparecida? In: OLINTO, Heidrun K. Histórias de literatura. As novas teorias alemãs. São Paulo: Ática, 1996. p. 224-239.

PERKINS, David. Is literary history possible? Baltimore: John Hopkins UP, 1992.

RESENDE, Beatriz. Contemporâneo. Expressões da literatura brasileira no século XXI. Rio de Janeiro: Casa da Palavra, 2008.

RICOEUR, Paul. A memória, a história e o esquecimento. Campinas, SP: Editora da Unicamp, 2007.

SILVA, Joaquim Norberto de Sousa. Modulações poéticas. In: ZILBERMAN, Regina; MOREIRA, Maria Eunice. O berço do cânone. Porto Alegre: Mercado Aberto, 1998. p. 89-142.

TASCA, Oscar. As vozes do romance. Coimbra: Livraria Almedina, 1983.

VIEIRA, Nelson. Hibridismo e alteridade: estratégias para repensar a história literária. In: MOREIRA, Maria Eunice (Org.). Histórias da literatura: teorias, temas e figuras. Porto Alegre: Mercado Aberto, 2003. p. 95-114.

Recebido em 21/04/2015.

Aceito em 25/09/2015 